\title{
El debate sobre el latifundio en la Argentina de entreguerras
}

\author{
ROY HORA
}

PALABRAS CLAVE: Argentina, entreguerras, cuestión agraria, latifundio.

\section{CÓDIGOS JEL: B30, K11, N56, Q15.}

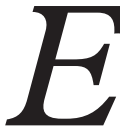

ste artículo estudia cómo fue pensado el problema rural en la Argentina en las tres décadas que corren entre 1910 y el estallido de la Segunda Guerra Mundial. En ese periodo, los productores agrícolas de la región pampeana enfrentaron dificultades de una intensidad hasta entonces desconocida, y ello dio lugar a reclamos y disputas que pusieron a la gran propiedad en el centro de la atención. El trabajo explora cómo se desplegó esta discusión, de qué maneras originales fue criticado el latifundio y cómo fue pensada su relación con el orden social y productivo. Se detiene, más que en contribuciones individuales, en las grandes ideas que dominaron el debate sobre el campo, y en el clima de ideas imperante en la opinión pública. Se refiere también al impacto de las nuevas visiones forjadas en la izquierda y la derecha. Finalmente, el trabajo explora las razones por las que el vasto consenso reformista forjado en esos años no dio lugar a iniciativas de transformación del régimen de tenencia del suelo de envergadura. 


\section{The agrarian question in Argentina in the interwar period}

\section{KEYWORDS: Argentina, interwar period, agrarian question, large property.}

\section{JEL CODES: B30, K11, N56, Q15.}

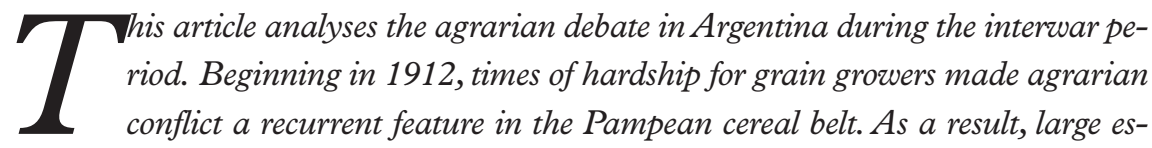
tates became the target of much criticism, both in the countryside and the city. This article explores changes in the way rural problems were depicted and discussed, focusing on the climate of ideas and the public mood rather than how individual authors analysed the agrarian question. A look at how the right and the left addressed rural issues also suggests that their contribution was of little significance. Finally, the article explores why the reformist consensus achieved during this period failed to transform the land tenancy structure.

Roy Hora [orcid.org/0000-0002-7303-4936] es profesor titular en el departamento de Ciencias Sociales de la Universidad Nacional de Quilmes (Argentina) e investigador principal en Conicet. Domicilio para correspondencia: España, 546 B, Florida (Argentina).C.e.:rhora@unq.edu.ar/rhora@udesa.edu.ar 


\section{INTRODUCCIÓN}

Este trabajo analiza cómo fue pensada la cuestión rural, con especial énfasis en el problema del latifundio, en la Argentina de las tres décadas que corren entre 1910 y el comienzo de la Segunda Guerra Mundial. En ese período, los productores agrícolas de la región pampeana enfrentaron dificultades de una intensidad hasta entonces desconocida, y ello dio lugar a reclamos y disputas que pusieron en el centro de la atención pública a la gran propiedad. El trabajo estudia cómo se desplegó esta discusión, de qué maneras originales fue impugnada la gran propiedad y cómo fue concebida su relación con el orden social y productivo.

El artículo se enfoca, más que en contribuciones individuales, en los grandes argumentos que dominaron la reflexión sobre el campo pampeano, y en el clima de ideas que imperaba en la elite dirigente y en la opinión pública. Presta especial atención a la manera en que la discusión sobre el latifundio se convirtió en un tema del debate ciudadano de amplia resonancia. Se refiere a cómo este problema fue abordado desde la izquierda y la derecha, y subraya la limitada incidencia de las nuevas propuestas político-ideológicas surgidas en la Europa de entreguerras.

El trabajo analiza por qué el vasto consenso crítico hacia la gran propiedad fracasó a la hora de impulsar un programa de división del suelo. Tradicionalmente, el fracaso del reformismo agrario se ha explicado atendiendo a la gravitación política de los grandes terratenientes pampeanos, cuyo poder no desapareció en la era del sufragio libre iniciada en 1912-1916 (Smith, 1967). Más recientemente, algunos autores sugieren que para comprender este fenómeno conviene colocar la atención en el plano discursivo. Allí observan, por una parte, la formación de un clima de ideas crítico hacia el latifundio y, por la otra, una disputa en torno al modo de interpretar la cuestión agraria del que los reformistas emergieron derrotados (Balsa, 2011).

Ambos abordajes presentan importantes limitaciones. Al centrar la atención en el plano económico-social o en el discursivo, se ahorran la tarea de analizar cómo estaba estructurado el espacio político en el que la crítica al latifundio surgió y encontró sus límites, y qué tipo de reformas estaban dispuestos a promover y financiar los actores de mayor relevancia política de la sociedad argentina. Este artículo presta atención a estas dimensiones y, a partir de ellas, enfatiza un conjunto de factores asociados a la política democrática, el dinamismo económico del sector exportador y la urbanización para explicar las principales limitaciones de las iniciativas de reforma del régimen de tenencia del suelo en un país en el que, todavía en vísperas de la Segunda Guerra Mundial, el sector agroexportador continuaba desempeñando un papel fundamental en la vida económica. 


\section{EL CONFLICTO AGRARIO EN LA ESFERA PÚBLICA}

$\mathrm{Al}$ igual que muchas otras agriculturas de exportación surgidas en la segunda mitad del siglo XIX, también en la Argentina los productores familiares, conocidos como chacareros, desempeñaron un papel fundamental en la expansión productiva que hizo de este país austral uno de los primeros exportadores mundiales de granos. Luego de tres décadas de sostenido crecimiento exportador, que transcurrió sin mayores conflictos, la disputa entre chacareros arrendatarios y terratenientes que estalló en el invierno de 1912 en Santa Fe, la segunda provincia agrícola del país detrás de Buenos Aires, marcó el inicio de una reevaluación de la naturaleza de los problemas de la agricultura y la sociedad pampeanas. El movimiento, iniciado en el distrito de Alcorta, fue la primera protesta de envergadura en la historia de la agricultura de exportación. La cuestión de la renta del suelo se ubicó desde el comienzo en el centro de la protesta. Al cabo de tres décadas de veloz expansión sobre la fértil pradera pampeana, el cierre de la frontera y la acrecida competencia entre los propios cultivadores por el acceso a los mejores lotes habían dado por resultado un sostenido incremento de los cánones de arrendamiento. El aumento de la incidencia de la renta en el resultado económico dio forma a un horizonte de mayores dificultades para los arrendatarios (amplia mayoría entre los cultivadores) y, en definitiva, terminó alterando lo que hasta ese momento había sido un escenario con escasos incentivos para la acción colectiva. Enfocando sus críticas en los dueños del suelo y sus agentes, los agricultores reclamaron una rebaja de los cánones de arrendamiento ${ }^{1}$.

El reclamo de los cultivadores pronto encontró la solidaridad, con frecuencia interesada, de todos los agentes económicos cuya suerte dependía de la prosperidad de los agricultores. Comerciantes, transportistas, proveedores de crédito y de servicios, incluso trabajadores rurales, se hicieron eco de sus denuncias contra el egoísmo de los terratenientes rentistas.Varios sacerdotes también colaboraron en la organización de la protesta y, de hecho, desempeñaron un papel tanto o más relevante que los agitadores socialistas ${ }^{2}$.

Es indudable que factores circunstanciales contribuyeron a la protesta chacarera, surgida tras dos años de dificultades. Pero el malestar de fondo era intenso y genuino, producto de factores que habían venido para quedarse. Es por ello que, por primera vez en la historia de la agricultura de exportación, una organización gremial como la Federación

1. El estudio más detallado sobre la expansión agrícola es DJENDEREDJIAN, BEARZOTTI y MARTiRÉN (2010). Visiones generales en AdELMAN (1994), BARSKy y GELMAN (2001), Míguez (2008) y Hora (2010 y 2012). Las mejores síntesis historiográficas son Míguez (2006, 2017). Sobre el conflicto agrario de 1912 y su legado, véanse ARCONDo (1980), ADELMAN (1989) y HALPERIN DoNGHI (1987).

2. Un relato de los principales sucesos en GrELA (1985). 
Agraria Argentina (FAA) logró implantarse en la campaña y promover reclamos colectivos entre un universo de arrendatarios que hasta entonces siempre habían preferido mejorar su condición a través de estrategias individuales, típicas de un grupo en el que predominaban los extranjeros poco arraigados en el país que los alojaba.

La formación de la FAA testimonia la maduración de la agricultura de exportación pampeana en dos aspectos decisivos. Por una parte, el incremento de los cánones de arrendamiento indica que la incorporación de tierra de frontera había llegado a su fin y, en consecuencia, que de allí en adelante el peso del arrendamiento sólo podría disminuirse por medio de la acción colectiva (Halperin Donghi, 1987). En segundo lugar, la existencia misma de la FAA revela la constitución de un sentimiento comunitario entre los agricultores o, al menos, de una mayor vocación por actuar de manera coordinada entre un conjunto humano que dos o tres décadas antes se hallaba más pendiente de lo que sucedía en sus lugares de origen del otro lado del Atlántico que en el poblado más cercano a su chacra o en los escenarios donde se decidía la suerte de la política argentina. La creciente densidad de los lazos gremiales y políticos entre los agricultores pone de relieve el proceso de integración de este segmento de la sociedad rural pampeana a la vida nacional, que continuaría profundizándose en décadas posteriores.

En este contexto, la concentración del suelo dejó de ser concebida-como lo era en el siglo XIX en tiempos de Sarmiento, Avellaneda o Juan B. Justo- como una temática que sólo despertaba el interés de sectores de la elite intelectual o de los grupos reformistas de la clase dirigente, que deseaban forjar una campaña poblada por empresas familiares de tipo farmer, dotadas de tecnología moderna y bien integradas al mercado. Desde Alcorta, por primera vez, actores sociales concretos, imbricados en la sociedad rural, sindicaron a la gran propiedad como la principal causa de las dificultades de la agricultura y, en definitiva, como el responsable último de la frustración del sueño de redimir a la pradera pampeana a través de la creación de un orden propietario de signo mesocrático. La moderación de la protesta seguramente contribuyó a que las demandas chacareras suscitaran pocas reacciones hostiles fuera del círculo de los terratenientes afectados por el reclamo. El propio gobierno santafesino no sólo medió en el conflicto, sino que volcó su influjo en favor de los arrendatarios (Halperin Donghi, 1987). De hecho, por cerca de una década los reclamos de los cultivadores giraron en torno a una distribución más equitativa del producto agrario, que creían posible alcanzar mediante una rebaja del canon de arrendamiento y limitando las prerrogativas de los terratenientes a la hora de establecer contratos por el uso del suelo.Y aun cuando no faltaron agricultores de simpatías socialistas e incluso anarquistas, la FAA se cuidó de impugnar de manera frontal el régimen de tenencia del suelo o el orden político, tal como les propuso el Partido Socialista (Adelman, 1989). 
Este programa moderado y conciliador encontró una cordial acogida en una sociedad de inclinaciones reformistas, y que por entonces se estaba tornando más crítica de la gran propiedad. La efervescencia política de esos primeros años de verdadera democracia sin duda favoreció la difusión de una retórica más agresiva hacia los poderosos, sobre todo cuando estos eran caracterizados como agentes económicos pasivos, como abusadores del trabajador y del hombre común. No resulta casual que el ascenso del debate sobre los problemas del campo coincidiera con los años de apogeo del georgismo. Con sus llamados a hacer caer todo el peso fiscal del Estado sobre la propiedad del suelo, el ideario de Henry George alcanzó su momento de máxima difusión en la década de 1910 (Hora, 2018). La crítica al latifundio arraigó, asimismo, en sectores antiliberales. La Iglesia católica, por ejemplo, comenzó a opinar sobre este tema, y no sólo a través de los sacerdotes que habían asistido la emergencia de la protesta chacarera. El latifundio [...] es contrario al fin primario de la propiedad, y por ende ha de ser reprimido, sostenía en 1914 monseñor Gustavo Franceschi, una de las voces más autorizadas de la Iglesia en cuestiones sociales ${ }^{3}$.

Otros registros nos permiten formarnos una idea aproximada de cuán extendida se hallaba esta sensibilidad antilatifundista en la conciencia popular. Los cambios en este terreno siempre esquivo para el análisis pueden rastrearse a través de algunos testimonios indirectos. El teatro es uno de ellos. Desde la década de 1920, observó Roberto Giusti, las representaciones del mundo rural prevalecientes en el género costumbrista el más popular de la dramaturgia en esas décadas- dejaron de girar en torno a las relaciones entre inmigrantes y nativos para enfocarse en las tensiones y disputas entre arrendatarios y terratenientes (Giusti, 1937: 257). El cine también refleja cómo cambiaron tanto los intereses de los autores como los gustos del público. En la pantalla, la crítica del terrateniente alcanzó una expresión muy elocuente con Nobleza Gaucha, un largometraje de inspiración criollista que fue la película argentina más vista de la era del cine mudo. Filmada en 1915, el argumento gira en torno a los esfuerzos de Juan, un joven trabajador rural, para recuperar a su amada María, raptada por un estanciero despótico y arbitrario con el fin de satisfacer su deseo de dominación y su apetito sexual (Di Núbila, 1998: 19) ${ }^{4}$.

Este ambiente crítico hacia la gran propiedad y las figuras que la representaban dejó su huella entre los partidarios del statu quo, que se tornaron más abiertamente defensores de los logros del pasado. Así, por ejemplo, Eleodoro Lobos (unos años antes ministro de Agricultura del presidente Sáenz Peña), en el prólogo que escribió en 1917 para

3. La Prensa, 4 de agosto de 1914. Para una descripción más detallada, véase Hora (2018).

4. La película puede verse en: https://www.youtube.com/watch?v=gfQ09kiPFXg 
el conocido estudio de Miguel Ángel Cárcano, Evolución histórica del régimen de la tierra pública, afirmaba que para avanzar hacia una mejor agricultura el ideal de un fraccionamiento racional mantenía toda su vigencia, pero que no necesitamos incautar la renta, defendernos de un monopolio imaginario, ni embarcarnos en utopías (Lobos, 1925: XXv). Los que abordaban la cuestión desde el punto de vista de los intereses terratenientes, como la Sociedad Rural, repitieron una y otra vez que la gran propiedad no constituía un problema, y que el latifundio, que ya pocos se atrevían a defender en público, seguía en retroceso; otros insistieron en que no había nada particularmente extraordinario en que un país que hasta muy poco antes poseía vastas zonas despobladas, y en el que la tierra era el factor productivo más abundante, tuviese grandes empresas agrarias. Pero todos estos argumentos perdieron verosimilitud, y aparecieron cada vez más como instrumentos de combate ideológico dirigidos a resguardar los privilegios de los poderosos. El tiempo en el que los grandes estancieros eran vistos como artífices del progreso agrario había pasado para no volver (Hora, 2002: 207-222).

Este panorama crítico ayuda a explicar por qué en 1921 la FAA decidió desplegar su protesta en la gran ciudad. La FAA había nacido en las cuencas cerealeras, y por varios años toda su acción estuvo concentrada en ese ambiente. Había fijado su sede en Rosario, eje de la región agrícola, donde también editaba su órgano de prensa, La Tierra. En agosto de 1921, la FAA promovió una marcha en la ciudad de Buenos Aires para presionar en favor de la sanción de una ley de arrendamientos que mejorara la posición negociadora de los chacareros. El 26 de agosto, mientras el proyecto era debatido en el Congreso Nacional, varios cientos de agricultores venidos de las cuencas cerealeras desfilaron a lo largo del eje cívico de la capital federal exhibiendo pancartas que impugnaban el orden imperante en el campo mediante consignas como: después de cien años del nacimiento de Alberdi, Echeverría, Sarmiento, Mitre [...] el 90 por ciento de nuestros hijos crecen analfabetos a la sombra del latifundio ${ }^{5}$.

El eco de esta protesta nos permite observar qué tipo de reacciones suscitaba la causa chacarera en la capital del país. El ambiente es completamente favorable a nosotros, se entusiasmaba La Tierra pocos días antes de la marcha ${ }^{6}$. Es importante advertir que este cálido recibimiento se extendió mucho más allá de las filas del Partido Socialista, que aspiraba a convertirse en su único vocero y aliado. También comprendió a figuras del universo político conservador, como Benito Villanueva, entonces presidente del Senado. Villanueva no sólo abrió las puertas de su despacho a los chacareros, sino que los colmó de promesas: Tendréis la ley que pedís.Y os digo más: la ley por cuya sanción habéis venido,

5. Una descripción del evento en BALSA (2011).

6. La Tierra, 23 de agosto de 1921, p. 1. 
no ha de ser más que el principio de una vasta legislación agraria, la legislación que os ha de dar la tierra en propiedad?

La gran prensa también celebró la demostración de los agricultores (Puiggrós, 1956: 244). Diarios como La Prensa y La Nación la retrataron como un capítulo más de la historia de manifestaciones pacíficas y respetuosas de las instituciones de la República que honraban la cultura cívica nacional. Al fin y al cabo, las pancartas de los agricultores impugnaban a los dueños del suelo, pero allí no estaban los nombres de Lenin, Kautsky o George, sino de los padres fundadores del liberalismo argentino y el Estado nacional.

Este clima de ideas en el que la visión del problema agrario comenzaba a ser reformulada atendiendo al punto de vista de los grupos subalternos, y el marco democrático en el que se estaba desplegando esta nueva narrativa sobre el campo, ayudan a explicar por qué el Congreso aprobó la ley de arrendamientos reclamada por la FAA en 1921 sin que ningún líder político que dependía del capricho de las urnas estuviera dispuesto a objetarla abiertamente (Hora, 2002: 255). Concebida para impedir los peores abusos de los propietarios, la ley 11.170 aseguró a los arrendatarios compensación por las mejoras introducidas en los predios, plazos contractuales más extendidos y mayor libertad para contratar servicios de terceros y para comercializar la cosecha. Y aun cuando, por defectos en su diseño, sus consecuencias prácticas fueron poco relevantes, la norma sancionada es reveladora de la extensión de la sensibilidad reformista. De acuerdo a un conocido experto agrícola, la ley, sin duda un paso hacia la estabilización de los agricultores, fue votada por los radicales, socialistas, conservadores y demócratas, como un testimonio de que estas ideas van haciendo camino en todas las colectividades políticas del país (Marotta, 1932: 95-96).

\section{EL LATIFUNDIO COMO PROBLEMA SOCIAL}

¿De qué modo fue concebida la cuestión agraria en esos años? Pese a que las intervenciones sobre el problema abordan una variedad de temas, con frecuencia analizados desde diferentes ángulos, los trabajos más influyentes surgidos en la estela del Grito de Alcorta presentan similitudes. Su foco gira en torno a las dificultades del agricultor-siempre identificado con la figura del cultivador que labra tierra ajena- para avanzar por el camino del progreso social. El peón rural y el trabajador sin tierra no ocuparon un lugar de relevancia en el debate, ni en las representaciones sobre la campaña, y ni siquiera los socialistas

7. La Tierra, 6 de septiembre de 1921, p. 1. Una descripción en Nuestra Tierra, v (95), septiembre de 1921. 
y más tarde los comunistas se ocuparon mucho de ellos. Los propietarios pequeños y medianos tampoco concitaron mayor atención, pese a que eran actores económicos de significación. Al igual que la producción dramática analizada por Giusti, las contribuciones de los especialistas se concentraron en la gran propiedad y la agricultura arrendataria. Por sobre todas las cosas, se enfocaron en las consecuencias sociales de un modo específico de organizar el cultivo de granos exportables que, ante todo, parecía estar golpeando a los cultivadores arrendatarios y destruyendo el sueño de una agricultura de granjeros independientes como la que en el siglo XIX se había desarrollado en las praderas de América del Norte.

Este énfasis en la frustración del ideal de sociedad rural forjado en el amanecer de la era constitucional constituye una novedad cuya importancia no siempre es debidamente apreciada. De hecho, fue recién tras Alcorta que la centralidad productiva del cultivo en tierra arrendada -rasgo característico de la agricultura de exportación- pasó a ser ampliamente concebida como el eje de la cuestión agraria pampeana. Es cierto que, desde los albores de la expansión cerealera y hasta los años del centenario, los expertos agrícolas habían formulado numerosas críticas a la producción basada en el arrendamiento, muchas veces apoyadas en la premisa de que la agricultura propietaria era superior. Pero mientras la frontera permaneció abierta y la estructura social se mantuvo fluida, el núcleo de las impugnaciones a este sistema de acceso a la tierra giró en torno al argumento de que el arrendamiento era poco adecuado para promover el cambio tecnológico, el laboreo inteligente y cuidadoso, y la preservación del suelo. En síntesis, se acusaba al arrendamiento de ser responsable de los problemas no tanto del presente como del futuro: la caída de la productividad, la baja de los rindes en el mediano o largo plazo, la destrucción de los recursos naturales.

Es comprensible que, en una etapa como la que va del ochenta al centenario, en la que, al calor de la expansión de la frontera productiva, la campaña experimentó vastas transformaciones sociales y fue testigo de un veloz y multifacético proceso de movilidad social, las principales limitaciones de la agricultura fuesen definidas como técnicas antes que como sociales, y se pusiera mucha atención en este plano. Es lo que se advierte en los trabajos de expertos agrícolas como Carlos Girola (1904), Eduardo Rañá (1904) y Emilio Lahitte (1905), o de analistas extranjeros como Karl Kaerger (2004). Este último, que ha sido calificado como el autor que ofreció la mejor descripción de las bases microeconómicas (Amaral, 2004: 11) de la agricultura en el fin de siglo, no creyó necesario detenerse a explorar el problema de la renta del suelo, en primer lugar porque, amén de su escasa significación en el resultado, entendió que estaba asistiendo, en muchos distritos, a un proceso de difusión de la propiedad que hacía del arrendamiento una fase de transición hacia la propiedad (Kaerger, 2004: 249). 
Pese a que ya en el fin de siglo el arrendamiento era objeto de críticas, por ejemplo porque estimulaba una agricultura de rapiña, sus limitaciones productivas no parecen haber sido tan considerables.Y ello no sólo porque era la dotación de factores de la región (tierra abundante y altos costos laborales), y no la modalidad de acceso al suelo, la causa primera que llevaba a los agricultores a optar por la explotación de grandes lotes, y por tanto por el laboreo superficial y poco cuidadoso, antes que por la labranza intensiva en pequeñas parcelas (por supuesto, el hecho de que muchos agricultores se concibiesen como extranjeros de paso, y en consecuencia vieran al negocio agrícola como una etapa en un ciclo de acumulación que no terminaba en el campo, también ayuda a explicar la preferencia por el arrendamiento) (Adelman, 1989; Djenderedjian, Bearzotti \& Martirén, 2010; Hora, 2010). También porque esa agricultura arrendataria no sólo se expandió con vigor por más de un tercio de siglo, sino que incluso acrecentó su participación en el mercado mundial una vez pasada la Gran Guerra. De hecho, hasta fines de la década de 1920 la agricultura pampeana también continuó incorporando tecnología a ritmo veloz ${ }^{8}$.

Desde los años del centenario, sin embargo, este horizonte que combinaba cambio social y expansión productiva comenzó a nublarse. El cierre de la frontera marcó el ingreso de la agricultura pampeana en una nueva etapa de su trayectoria, sobre todo porque incidió sobre el precio del suelo. En un contexto marcado por el alza de los arrendamientos, los agricultores vieron reducidos sus márgenes de utilidad y sus oportunidades de acumulación. $Y$ en los momentos más difíciles que vinieron tras Alcorta, en particular durante la guerra y la inmediata posguerra, ello se acompañó de una caída del ingreso que comprometió la idea de que el negocio agrícola era una buena opción para mejorar la propia condición en el mediano y largo plazo. La estructura social de la campaña se estaba volviendo más rígida, y sólo distritos alejados (como el sur bonaerense) mantuvieron abiertas algunas avenidas de progreso económico y ascenso social. Pasada la etapa de entusiasmo propio de los años del boom exportador del cambio de siglo, el campo dejó de ser un espacio hospitalario para los que soñaban con la gran aventura del ascenso social.

De allí que, en el período de entreguerras, predominara una línea de reflexión que abordó los problemas del campo desde una perspectiva social antes que puramente técnica, enfatizando la interacción entre la eficiencia económica, el progreso social individual y familiar, y el bienestar de la comunidad. Un punto común de los diagnósticos elaborados tras Alcorta era que lo que estaba en problemas no era la agricultura, sino, ante todo, los agricultores y la sociedad rural. Se estaba, afirmaba un experto, ante la disolución de nuestra familia rural, que tan lozana habia sido en el anterior periodo de prosperi-

8. La gran novedad de la década de 1920 fue la cosechadora mecánica y el tractor con motor a explosión (GERCHUNOFF, 2016). 
dad agraria (Campolieti, 1929: 11).Y a la hora de buscar responsables la culpa cayó sobre el latifundio y su principal consecuencia, la agricultura arrendataria. Bajo este prisma, la división de la gran propiedad y la creación de una agricultura de propietarios aparecía como el único camino para darle nueva vitalidad a la sociedad rural (Girbal de Blacha, 1989).

Pedro Marotta y Roberto Campolieti, agrónomos de prestigio y dilatada carrera, nos ofrecen ejemplos típicos de este abordaje, también dominante entre muchos otros analistas del campo de esos años (Lázaro Nemirovsky, Celestino Sienrra y Juan L. Tenembaum, entre otros muchos). En el centro del problema agrario, sugerían todos estos autores, estaban los males creados por el latifundio y la agricultura arrendataria. La gran propiedad, argumentaban, era la principal responsable de la existencia de una clase de productores itinerantes que carecían de todo incentivo para invertir en las tierras que alquilaban o para nutrir la vida comunitaria local. Este sistema agrario era incapaz de promover el cambio tecnológico y la inversión de capital, puesto que, al impedir el acceso de los inquilinos a la propiedad de la tierra, también dificultaba su acceso al crédito, así como la cooperación entre los agricultores en las tareas de financiación y comercialización de la cosecha. La agricultura arrendataria, enfatizaban, distribuía el ingreso de manera muy desigual y creaba una sociedad con escasa vida asociativa, déficits de vivienda, y grandes limitaciones en la oferta educativa, sanitaria y cultural. El problema no eran sólo los agricultores empobrecidos, sino el empobrecimiento de la sociedad rural: la fragilidad de su tejido productivo, pero también la precariedad de su universo asociativo y su espíritu comunitario (Campolieti, 1929; Marotta, 1932).

\section{OBSTÁCULOS A LA REFORMA DEL LATIFUNDIO}

Pero aun si la denuncia del latifundio y sus consecuencias sociales creció como nunca antes, su incidencia sobre el futuro del país terminó siendo menor de lo que este clima de impugnación parecía sugerir. Recogiendo un argumento que algunos contemporáneos en particular los socialistas- hicieron suyo, se ha sugerido que ello fue resultado de la influencia y el peso político que todavía conservaban los grandes terratenientes pampeanos. Muchas veces se ha repetido el argumento de que los ministros de Agricultura se reclutaban entre los socios de la Sociedad Rural (Smith, 1967). Ello es menos sorprendente de lo que podría parecer, dado que esta asociación, además de reunir a grandes terratenientes, también contaba entre sus cerca de dos mil socios con empresarios de menor cuantía y con expertos agrícolas. De hecho, ninguno de los ministros de la era radical (Pueyrredón, Demarchi, Vargas Gómez, Rodríguez, Le Bretón, Mihura, Fleitas) pertenecía al sector más poderoso de la elite ganadera. 
Más importante es que, en esos años, los principales hitos de la política agraria (como las leyes de arrendamiento de 1921 y 1932) no se definieron en el Ministerio de Agricultura, sino en el Parlamento.Y ello invita a dirigir la atención hacia un aspecto más relevante. Esta visión instrumentalista, que tiende a proyectar al ámbito político formas de poder propias de la esfera económico-social, es poco sensible a los cambios que la reforma de 1912 y la democratización de la vida pública, que fue su principal consecuencia, introdujeron en la relación entre gobernantes y gobernados. Y ello no sólo por la renovación que en esos años experimentó el elenco parlamentario y más en general la clase política. Al observar el panorama desde una perspectiva más amplia que la referida a la composición de los gabinetes, se advierte que los agricultores, pese a que pudieron organizarse para dar a conocer sus puntos de vista e, incluso, fueron cortejados por distintos actores políticos, debieron moverse en un terreno en el que otras voces y otros intereses poseían mayor incidencia en el debate público, la vida electoral o la disputa por recursos.

En verdad, la democratización creó un contexto favorable para el ascenso de una corriente de crítica al latifundio en la opinión pública, pero a la vez le asignó al tema un lugar periférico en la agenda política. Cuatro motivos interconectados explican este desplazamiento. Por una parte, la emergencia de una nueva elite dirigente, crecida al calor de la movilización popular y más sensible a las demandas provenientes desde abajo, volvió más opaco e indirecto el vínculo entre la elite terrateniente y el Estado que en tiempos de la república oligárquica. Ello afectó sobre todo a los críticos del orden rural ubicados a la izquierda del arco político-ideológico. Luego de 1912-1916, los argumentos de los socialistas sobre la importancia de la gran propiedad rural como la base política del poder propietario, que luego se proyectaba sobre las instituciones de la República, se volvieron menos convincentes. El latifundio suscitó el repudio de muchos; pero en esos años se reveló como un problema que, si bien podía afectar a la sociedad rural pampeana, no tenía mayor relevancia en la política nacional.

Ello fue así porque, con un 57,3\% de población urbana en 1914, la Argentina era un país más urbanizado no sólo que Brasil, Estados Unidos o Canadá, sino que Francia o Alemania. Ello contribuye a explicar por qué, tras la reforma electoral, la expansión de la participación popular en la vida pública se sintió con mayor fuerza en las ciudades, y benefició en primer lugar a los grupos mejor organizados y a los más numerosos. La creciente importancia del electorado urbano, sumada a la relativa debilidad del sindicalismo agrario y chacarero, hicieron que los sectores dirigentes de la era del sufragio libre tuvieran pocas razones para promover los temas de la agenda rural y, en particular, cualquier proyecto dirigido a reformar el régimen de tenencia del suelo. Pese a su eco en el debate público, esa reforma era una demanda de un sector minoritario. Incluso en las tres ma- 
yores provincias agrícolas, Buenos Aires, Santa Fe y Córdoba, los 58.000 arrendatarios que registra el censo de 1914 representaban menos del 5\% de la población masculina adulta total de esos distritos, y un porcentaje aun menor de la habilitada para votar, que alcanzaba a 1,5 millones. El hecho de que el porcentaje de extranjeros entre los agricultores fuese bastante más alto que en el resto de la población hizo que su causa tuviese aún menos atractivo para las organizaciones partidarias.

El tercer factor que restó importancia al problema del latifundio fue el sostenido dinamismo del sector exportador. Pasados los años de la Gran Guerra y la crisis de posguerra, el país vivió una etapa de expansión económica en la que las exportaciones de granos desempeñaron un papel crucial (en parte, gracias a la retracción de la oferta rusa). En consecuencia, en los dorados años veinte, y pese al cada vez más amplio consenso en torno a las limitaciones sociales del orden rural, ¿cuáles eran los incentivos de los grupos dirigentes para alterar el funcionamiento de un sector productivo que había hecho de la Argentina el granero del mundo, máxime teniendo en cuenta que no había actores políticos de peso comprometidos con este programa? Los costos de una iniciativa de este tipo, por ejemplo, en términos de desorganización productiva, podían ser más elevados que las ventajas que prometía ofrecer. Y esas ventajas, que no eran obvias ni inmediatas para la población urbana, sólo se verían, quizás, en el largo plazo.

Finalmente, también es preciso considerar la cuestión nada irrelevante de los costos económicos de una reforma agraria. Descartada de plano la opción de una expropiación lisa y llana -que ni siquiera los socialistas promovían-, no estaba para nada claro cómo afrontar los costos de un programa de indemnizaciones a los propietarios expropiados o forzados a fraccionar sus propiedades que, inevitablemente, tenía que financiarse con más impuestos. La suerte del proyecto de reforma del sistema de pensiones impulsado por la Administración Alvear en 1923-1924, derrotado por los empresarios, pero sobre todo por los trabajadores que debían contribuir a solventarlo, es reveladora del escaso margen de maniobra del Estado a la hora de incrementar la carga tributaria (Horowitz, 2001). Una cosa era criticar el latifundio; otra, muy distinta, era pagar por su desaparición.

No es casual que todas las grandes reformas agrarias de los años de entreguerra en el Viejo Continente pudieran avanzar entre otras cosas porque su peso cayó sobre una clase terrateniente que pasó a ser concebida como mayoritariamente extranjera (en los nuevos países de la Europa oriental que surgieron tras el derrumbe de los imperios multiétnicos) o porque la expropiación fue parte de una derrota política más amplia de los terratenientes y del Estado que los apoyaba (en Rusia). Algo similar puede decirse respecto a América Latina. La reforma agraria en México no hubiese tenido lugar de no haber sido por la Revolución y la quiebra del porfiriato. En países como la Argentina, que en esos años no su- 
frió grandes cataclismos políticos y siguió encarrilado en la senda constitucional, estas opciones no estaban abiertas. De allí que quien hiciera suya la agenda de reforma de la gran propiedad no podía esperar importantes ganancias políticas y difícilmente encontrase aliados fuera del círculo, por definición pequeño, de los grupos inmediatamente beneficiados. En el amanecer de la era democrática, pues, la voz de los agricultores -y más en general los intereses rurales- se volvió menos relevante en la escena política, desplazada por el peso creciente de actores urbanos.Y con ello se perfiló una divergencia de destinos entre campo y ciudad que el paso de los años no haría sino acentuar.

\section{LA GRAN DEPRESIÓN}

Los problemas de la agricultora de exportación alcanzaron una intensidad inédita cuando el país sintió el impacto de la Gran Depresión. El derrumbe de los precios agrícolas producido por ese cataclismo trajo dificultades para todos los que dependían del ingreso rural. Golpeados por el derrumbe del mercado mundial, muchos terratenientes vieron mermado su ingreso y acrecidas sus deudas, y no pocos terminaron en la ruina. El deterioro de las grandes residencias rurales construidas en la Belle Époque, el alto nivel de endeudamiento y la liquidación de tierra ofrecen testimonio de dificultades considerablemente más graves y generalizadas que las que los estancieros enfrentaron a comienzos de la década de 1890 o en los años de la crisis ganadera de 1921-1924. Estas constricciones no podían sino traer una caída en el nivel de inversión, y con frecuencia también una mayor presión sobre sus arrendatarios, que pareció confirmar las denuncias de egoísmo, arcaísmo tecnológico y falta de disposiciones empresariales de muchos terratenientes. En esos años, el desvanecimiento de la figura del estanciero modernizador y su reemplazo por la del terrateniente rentista y parasitario terminó de completarse. Desde entonces la imagen de un sistema de relaciones productivas del que ya no podía esperarse nada bueno se volvió hegemónica (Hora, 2002: 279-281).

Pero si las estrecheces de los poderosos pasaron casi desapercibidas fue ante todo porque los agentes más débiles de la cadena productiva sufrieron la Depresión con mayor dureza. Pequeños agricultores, trabajadores rurales y, sobre todo, chacareros arrendatarios, concitaron la atención de un país sensibilizado ante una desdicha cuya forma más extrema fue la caída en la pobreza y la expulsión de la tierra.Y aun cuando es claro que este cruel destino sólo afectó a una porción muy minoritaria de los agricultores, las penurias de esos chacareros errantes terminaron de reafirmar la idea de que esa campaña donde imperaba el latifundio debía dar paso a un nuevo orden rural, basado en una agricultura de propietarios. El contraste entre la opulencia de los grandes estancieros (que era cada vez más un recuerdo del pasado) y la penuria de los chacareros sin horizontes 
pasó a representar el ejemplo más clamoroso de la iniquidad y las falencias del orden social argentino.

En 1932, la extendida conciencia de que los agricultores enfrentaban enormes dificultades hizo posible una reforma de la ley de arrendamientos de 1921, que se tornó más favorable a los chacareros. Pero en la medida en que los precios del cereal siguieron deprimidos hasta mediados de la década y la demanda de tierras productivas superaba a la oferta, esta reforma no logró mejoras considerables en la posición negociadora de los arrendatarios. Un poco más tarde, el establecimiento de un piso mínimo de precios para el grano sirvió para mantener el nivel de actividad, pero trajo poco alivio a los cultivadores.

En estas circunstancias, socialistas y comunistas creyeron que había llegado el momento de poner de pie a las víctimas del derrumbe de la agricultura o, al menos, de convertir esta temática en un foco de agitación. Sin embargo, la campaña contra las iniquidades del orden rural promovida por la izquierda cosechó pocos éxitos. Ya en 1933 se hizo claro que la población rural le daba la espalda a los débiles intentos de actores ampliamente percibidos como políticamente irrelevantes y, además, como extraños al asociacionismo agrario e incluso a la sociedad rural. De hecho, la manifestación más elocuente del infortunio campesino no fue un incremento de la militancia agraria, sino la aceleración de la migración hacia los centros urbanos, que el paso de los años no hizo decrecer.

Pese a toda su dureza, y a su vasto impacto, tanto en el campo como en la opinión pública urbana, la Gran Depresión no introdujo una inflexión decisiva en la manera de conceptualizar los problemas del campo. Es significativo que los estudios más influyentes sobre la cuestión rural aparecidos en el período de entreguerras fueron escritos antes de 1930 (los ya citados de Marotta y Campolieti, pero también La burguesía terrateniente, del socialista Oddone), o muy poco después (como es el caso de Estructura económica y orientación económica de la agricultura argentina, de Lázaro Nemirovsky, publicado en 1933). Estos trabajos alcanzaron mayor impacto y difusión al calor de la Depresión, pero su enfoque y su temática se forjaron en la etapa previa. Con la única excepción del marxista José Boglich $(1933,1937)$, que interpretó la crisis a la luz de una perspectiva leninista y catastrofista -típica del análisis marxista del tercer período- y cuyo horizonte era la agricultura socializada, los demás estudiosos continuaron encuadrando sus contribuciones en el marco de una tradición de interpretación que ya tenía dos décadas de vida. En verdad, la frustración del sueño de un campo de pequeños propietarios se forjó tras Alcorta, y la Depresión no hizo más que confirmar los aspectos más pesimistas del diagnóstico elaborado en los años que sucedieron a esa movilización agraria. 


\section{IZQUIERDA Y DERECHA EN LAS CHACRAS PAMPEANAS}

Podría agregarse, incluso, que el curso de los acontecimientos conspiró contra las posiciones de la izquierda, haciendo que sus propuestas perdieran atractivo intelectual y gravitación política. Cuando comenzó la Depresión, las simpatías hacia las posiciones socialistas que eran visibles en los años de emergencia del movimiento chacarero, aunque siempre minoritarias, habían terminado de esfumarse. Para entonces, la idea de que un agricultor socialista podía llegar a presidir la FAA, como había sucedido brevemente con Antonio Noguera en 1912, parecía una quimera. Resulta algo irónico comprobar que la desaparición de todo rastro de influjo socialista en el campo haya tenido lugar precisamente cuando el deseo de acceder a la propiedad del suelo, que este partido habían estimulado desde que Justo presentó su programa agrario en 1901, por fin se había vuelto predominante entre los arrendatarios.

El retroceso socialista se aceleró en el curso de la década de 1920 y fue empujado, en gran medida, desde la propia FAA. A partir de comienzos de ese decenio, su presidente Esteban Piacenza, que había iniciado su carrera pública cerca del Partido Socialista, orientó a la FAA hacia una política muy pragmática, sustentada en la premisa de que cualquier mejora en su posición negociadora y cualquier victoria en la disputa con los dueños del suelo o con el sector de comercialización dependía más de los lazos de la FAA con los actores más poderosos del sistema político (radicales y conservadores) que de su relación con fuerzas que, como el socialismo o el comunismo, carecían de incidencia sobre las orientaciones del Estado nacional y las administraciones provinciales. Más que ideas, pensaba Piacenza, lo que la FAA necesitaba era el reconocimiento y el apoyo de los gobernantes. En esta deriva que invitaba a la moderación, la FAA tomó distancia de los partidos de izquierda, hasta convertirse en uno de sus críticos más acérrimos ${ }^{9}$.

Llegado este punto, hay que advertir de que la divergencia de objetivos postulada por Adelman (1989) para explicar por qué los socialistas de comienzos de siglo no lograron liderar la protesta rural debe complementarse con otros argumentos más propiamente políticos. Lo que terminó alejando a los agricultores de los socialistas y un poco más tarde de los comunistas no fue sólo una divergencia de visiones e intereses. La irrelevancia política de la izquierda y la permeabilidad de los partidos en el Gobierno a escuchar las demandas chacareras y a reconocer legitimidad a la FAA tuvo mayor peso. Desde el punto de vista de los agricultores, la izquierda no tenía nada que radicales y conservadores no pudieran ofrecerles, siquiera en cuentagotas y de manera mezquina y selectiva (el único premio que podía cosechar este grupo relativamente marginal desde el punto de vista po-

9. Sobre la FAA, véanse Bonaudo y Godoy (1985), y Federación Agraria Argentina (1939). 
lítico). Las quejas que el izquierdista Boglich formulaba en 1920 sobre el coqueteo entre lo que denominaba políticos burgueses y los agricultores revelan que, desde muy temprano, esas relaciones eran bastante fluidas ${ }^{10}$. La sanción de la ley de arrendamientos de 1921 confirmó que estos vínculos eran más próximos de lo que los jefes chacareros, que gustaban de proclamar su completa orfandad, estaban dispuestos a admitir en público. En años posteriores, esos lazos continuaron estrechándose, y no sólo con los radicales. En los distritos administrados por conservadores, los contactos también estuvieron a la orden del día, tanto en la década de 1920 como en la de 1930.

Por ello, no puede sorprender que el atractivo de un actor como el comunismo, de discurso más radical y de inserción aún más marginal que el socialismo, tanto en la campaña como en el sistema de poder, fuese insignificante. De allí que, incluso en el peor momento de la Depresión, cuando la desesperación debe haber ganado a muchos agricultores empobrecidos, el retroceso socialista no abrió el camino para ningún avance de los comunistas y, más bien, tendió a consolidar las orientaciones más pragmáticas y moderadas del gremialismo chacarero. En esos años, los comunistas argentinos estuvieron muy lejos de poder emular los modestos pero reales logros organizativos alcanzados por sus camaradas de causa en el medio oeste americano que les permitieron, si no dirigir, al menos participar activamente del ciclo de protestas agrarias de 1932-1935 (Dyson, 1982). El hecho de que el círculo dirigente de la FAA no creyese necesario ocultar su admiración por el gobierno fascista italiano, y que su vocero La Tierra reprodujese de vez en cuando artículos del diario filonazi Crisol (sobre temas como la importancia de la agricultura propietaria, por ejemplo, o sobre las virtudes del gobierno de Manuel Fresco [1936-1940], simpatizante local de Mussolini) ofrece una indicación adicional sobre la muy acotada relevancia de las ideas de izquierda en el campo pampeano ${ }^{11}$. A la luz de esta evidencia, parece razonable concluir que, si en los años treinta el gremialismo chacarero sintió el influjo de alguna experiencia extranjera, esta no provino de la izquierda, sino de la derecha.

Con todo, hay que señalar que la actitud favorable hacia el fascismo exhibida por los directivos de la FAA no pareció ofuscar, pero tampoco cautivar, a la comunidad de agricultores a la que ese grupo dirigente pretendía orientar. Sin duda, entrados los años treinta el Gobierno italiano todavía no era percibido como un régimen sanguinario y asesino, sino como una opción política legítima, digna de reconocimiento. En Argentina, además, el fascismo tenía otro atractivo, sobre todo para una comunidad como la chacarera, en cuyo seno los inmigrantes italianos eran un grupo muy significativo: gracias a los logros de su

10. La Tierra, 30 de enero de 1920, pp. 2, 3.

11. Véase, por ejemplo, Enrique Osés, «La redistribución de la tierra argentina», Crisol, 23 de septiembre de 1936, p. 1. 
primera década de vida, ese régimen ayudó a contrarrestar el prejuicio antipeninsular que había imperado en el país desde el comienzo de la gran inmigración, y que los habitantes de ese origen había sufrido de muchas maneras (Newton, 1997). El hecho de que una figura comoVittorio Valdani pudiera combinar el entusiasmo por la causa fascista con un lugar en el directorio de la Unión Industrial Argentina, o que la liberal Victoria Ocampo aceptase entrevistarse con el Duce en 1934, dice mucho sobre el prestigio del gobierno de Mussolini entre los grupos dirigentes argentinos. Por otra parte, las credenciales agrarias del fascismo no eran insignificantes, sobre todo si atendemos a su programa social: el régimen manifestaba preocupación por el bienestar de los campesinos y el progreso de la agricultura, se pronunciaba en favor de la expropiación de los grandes terratenientes y reivindicaba la producción familiar. Sus limitaciones en este terreno, sin embargo, también eran muy patentes, tal como lo revela su «batalla del trigo». El hecho de que la Italia fascista ni siquiera pudiese alimentar a su propia población le restaba atractivo práctico a sus propuestas para un grupo que, como el chacarero, no se caracterizaba por su interés en el debate de ideas.

Todo ello sirve para entender por qué las posiciones más extremas de lo que en Europa era un momento de intensas disputas ideológicas tuvieron poco eco en la pampa. Para los hombres que reflexionaban sobre el campo, los problemas rurales siguieron enmarcados en el cauce liberal y constitucional en el que funcionaba la política nacional. El triunfo de comunistas y fascistas en los países situados al otro lado del Atlántico no alteró este cuadro. La colectivización nunca sedujo a los agricultores o los trabajadores pampeanos, que tampoco sintieron que las propuestas del fascismo tenían mucho que ofrecerles.

De hecho, el creciente eco de la sensibilidad nacionalista constituye una novedad más significativa del clima cultural de esa Argentina que poco a poco le volvía la espalda al cosmopolitismo, tanto en la ciudad como en el campo. El ascenso del nacionalismo también contribuye a explicar el moderado eco de las nuevas experiencias políticas europeas entre la población rural. Empujado por estímulos que venían de la escuela, el deporte y las industrias culturales, en la campaña el nacionalismo arraigó con fuerza sobre el fértil terreno que le ofrecía el creciente peso demográfico de las nuevas generaciones, donde los nativos predominaban sobre los venidos de Europa. De allí que para la década de 1930 la impugnación a los dueños del suelo se dotó de nuevas aristas que ahora denunciaban, además de su elitismo político y su egoísmo social, su carácter europeizante. Al mismo tiempo, el desembarco en la campaña de capitales extranjeros se volvió un motivo de preocupación o, al menos, un tema de agitación.

El conservador Manuel Fresco fue uno de los hombres de Estado que se propuso articular políticamente esta sensibilidad nacionalista. Sus iniciativas ponen de relieve las 
transformaciones que estaba experimentando la visión conservadora del problema rural. Cada vez más alejado del liberalismo que su partido había cultivado durante la etapa de construcción del Estado, Fresco no renunció, sin embargo, a definirse como el líder de una fuerza identificada con el hombre común y promotora del progreso social. Durante su paso por la gobernación bonaerense, este crítico de la democracia parlamentaria llamó a acelerar el proceso de división de la tierra y realizar de una vez por todas el postulado social de darla en propiedad a los que la trabajan (Fresco, 1941: 108). Al igual que la izquierda, también denunció al capitalismo imperialista que, sacando ventaja del estado circunstancial de pobreza de nuestros ricos criollos, ha adquirido por poco menos que centavos los mejores establecimientos (Fresco, 1941:39). Esta retórica antilatifundista era algo más que un ejercicio vacío. Fresco creó un Instituto Autárquico de Colonización, que a lo largo de sus cuatro años de gobierno expropió unas setenta mil hectáreas para destinarlas a la creación de pequeñas empresas agrarias (Blanco, 2007: 120). Esta iniciativa contó con el apoyo entusiasta de la FAA, que en esos años se mostró muy cerca del gobierno conservador $^{12}$.

Los motivos nacionalistas también se observan en el discurso de la dirigencia de la FAA, y eran en rigor más relevantes que sus elogios al fascismo italiano. No debe haber ya millones de hectáreas poseídas por sociedades anónimas o por capitalistas, muchos de aquellas y de éstos residentes en el extranjero, proclamaba Piacenza ${ }^{13}$. Hasta los socialistas se volvieron permeables a este discurso. Alfredo Palacios, por ejemplo, creía que había llegado el momento de acabar con la concentración de grandes extensiones en manos de las empresas extranjeras ${ }^{14}$. Todo ello sugiere que el ascenso de la retórica nacionalista, más que abrir el camino para un diagnóstico alternativo, se articuló con visiones previas para, de este modo, reafirmar los grandes lineamientos en cuyo seno se había venido pensando el problema de la tierra. En todo caso, la denuncia del carácter extranjero o antinacional del terrateniente agregó un factor adicional de impugnación a un cuadro cuyos trazos gruesos ya habían sido definidos en los años de Alcorta, y que seguía viendo en la pequeña propiedad familiar el norte hacia el que el campo argentino debía orientarse.

\section{CONSENSOS EN LA ELITE POLÍTICA}

La amplitud de este consenso reformista puede observarse en el debate parlamentario que culminó con la creación, en 1940, del Consejo Agrario Nacional. El CAN tenía por ob-

12. La Tierra, 29 de septiembre de 1936.

13. La Tierra, 4 de julio de 1944, p. 3.

14. Congreso Nacional, Diario de Sesiones de la Cámara de Senadores, 1940, I, pp. 577, 589. 
jeto facilitar el acceso al suelo a las familias de agricultores arrendatarios, cediéndoles tierras públicas o expropiadas al efecto. El debate legislativo que culminó con la sanción de la ley 12.636 ayuda a poner de relieve -aún en esa década en la que las referencias ideológicas del debate político se habían expandido con respecto al panorama prevaleciente en la era oligárquica o en la radical- todo lo que había de común en la manera de ver el problema rural en las filas radicales, socialistas y conservadoras y, por extensión, entre aquellos sectores de la opinión que se sentían interpelados por los tres grandes partidos con representación parlamentaria. José María García se ocuparía de recordarlo unos años más tarde. La ley del Consejo Agrario Nacional, señaló este publicista comunista, fue sancionada por el Congreso Nacional en 1940, a iniciativa de los legisladores del Partido Demócrata Nacional de Córdoba, del radicalismo y del socialismo, y con la presión del Partido Comunista, pues sus militantes promovían grandes movimientos obreros y campesinos por la Reforma Agraria (García, 1972: 30-31). Si dejamos de lado las peregrinas afirmaciones de García sobre la relevancia de su organización, el resto del argumento era en esencia cierto.

En efecto, la creación del Consejo Agrario, promovida por el oficialismo, fue acompañada por toda la oposición parlamentaria. En la plataforma electoral que presentó para las elecciones de 1937, el radicalismo había incorporado una propuesta de reforma agraria, con normas para evitar los latifundios, las tierras ociosas y la concentración. Este programa inspiró la posición que el radicalismo asumió en el debate de 1940. Tanto es así que cuando le tocó defender el proyecto, el diputado Bernardino Horne, firmante del despacho de comisión y vocero de la bancada radical, afirmó que ya nadie dudaba de la existencia del grave problema de la tierra concentrada en pocas manos $\mathrm{y}$, sobre la base de ese vasto acuerdo, solo se discute la forma y procedimientos para terminar con ese estado de cosas. Ese orden indignante e injusto, agregaba Horne, había llevado al trabajador rural a perder sus tierras, y a ser un paria dependiente del latifundista, nuevo señor feudal de la actual organización económica ${ }^{15}$.

Los conservadores coincidían. Durante el debate, un legislador de esa bancada condenó al orden agrario que mantenía a la nación despoblada y a sus hijos vagabundos y errantes en su propia patria ${ }^{16}$. Pese a que el ya citado García prefería no acordarse, no sólo las fracciones más progresistas y liberales del conservadurismo dieron su apoyo a la creación del CAN. Daniel Amadeo y Videla, alineado con Fresco, también sostuvo que había quedado demostrado que el país entero reclama esta ley, cuyo sentido emparentaba con

15. Congreso Nacional, Diario de Sesiones de la Cámara de Diputados, 1939, II, p. 208.

16. Id., p. 206. 
la obra agraria de su jefe político ${ }^{17}$. Otro conservador agregó que el interés social y colectivo imponen la conveniencia y la necesidad de que la tierra pertenezca en primer término a los que la trabajan ${ }^{18}$.

Los socialistas, por su parte, sumaron su apoyo a una iniciativa que entendían bien orientada, aunque demasiado moderada. En la voz de Nicolás Repetto, celebraron la aceptación del principio de expropiación con fines de interés social, pero advirtieron de que, en tanto no se había votado fondos suficientes, la ley no podía alcanzar sus ambiciosos objetivos $^{19}$. Enrique Dickmann también señaló la amplitud de ese verdadero clamor contra el latifundio, y se lamentó de que los chacareros carecieran de suficiente fuerza política como para empujar la reforma más allá ${ }^{20}$.

Así, pues, el último gran debate parlamentario sobre la cuestión agraria de la era exportadora puso de manifiesto la amplitud del malestar con el orden imperante en el campo pampeano. En este sentido, la creación del Consejo Agrario Nacional no fue, como aventuró Horacio Giberti en sus memorias, una propuesta aislada e irrelevante de la elite gobernante de la era del fraude, destinada a favorecer a los terratenientes expropiados (Ramírez, 2011: 166). Fue, más bien, el producto de esa visión crítica de la gran propiedad que, con énfasis y modulaciones particulares, se extendía desde el socialismo al conservadurismo. El propio Boglich no tenía dudas sobre el alcance de esta extendida preferencia por la pequeña propiedad familiar y en su libro de 1937 ya había señalado que los principales proyectos de ley discutidos en esos años (de los cuales el de 1940 sería el último y más importante) no obstante haber sido presentados y patrocinados por partidos políticos de filiación diversa, no difieren entre sí más que en la forma (Boglich, 1937: 259). Si no hubo reforma, la explicación debe buscarse en otro lado: en las dificultades para traducir este consenso en un programa dotado de apoyos lo suficientemente sólidos como para permitir su avance.

\section{LOS LÍMITES DEL PROGRAMA REFORMISTA}

El contraste entre la amplitud del sentimiento antilatifundista puesto de manifiesto en la creación del CAN y sus resultados efectivos resulta lo suficientemente importante como

17. Id., p. 575 .

18. Id., pp. 202, 209. También Congreso Nacional, Diario de Sesiones de la Cámara de Senadores, 1940, I, p. 629.

19. Congreso Nacional, Diario de Sesiones de la Cámara de Diputados, 1939, II, p. 304.

20. Id., p. 540 . 
para justificar que volvamos a explorar, desde el mirador que nos ofrece el año 1940, el problema de la debilidad de las fuerzas que favorecían la reforma rural. Como ya hemos argumentado, sus principales determinantes, así como, más en general, las limitaciones de todas las iniciativas de reforma agraria de la era agroexportadora, no remiten al plano de las ideas que animaban a los principales actores del sistema político argentino, sino, de modo más concreto, a las constricciones que acotaban las opciones que los grupos gobernantes tenían ante sus ojos. En el debate parlamentario, el propio Dickmann se ocupó de recordar que si esa vasta insatisfacción con el latifundio no iba más allá era porque a sus víctimas les faltaba cohesión y peso político. Sin embargo, algunas novedades de esos años merecen atención, y nos ayudan a completar el panorama del problema de la tierra en vísperas de la Segunda Guerra Mundial.

El primer aspecto que señalar es que, cuando las divisiones blindadas alemanas comenzaban su avance sobre Francia, los grupos dirigentes argentinos seguían confiando en que el patrón de crecimiento agroexportador constituía la opción más conveniente para promover el desarrollo del país y diversificar su estructura productiva, aun si una parte de la población del campo quedaba al margen de sus beneficios. El poder social y el influjo político de los terratenientes (todavía entonces eran el grupo más rico de la elite propietaria) no debe ignorarse, pero no estaba allí el mayor obstáculo para poner en marcha iniciativas que afectaran sus intereses. Pese a todas las tensiones derivadas de la caída del ingreso agrario y el deterioro de la calidad de vida de los habitantes de la campaña en los años inmediatamente posteriores a la Depresión, la recuperación de la agricultura de exportación en la segunda mitad de la década volvió evidente que la gran propiedad y la chacra arrendada eran las unidades de producción más conspicuas de una economía agraria que, con todas sus falencias, y en un mercado mundial enrarecido y que viraba hacia el proteccionismo, todavía conservaba mucho de su dinamismo económico. Alterar ese equilibrio, sobre todo si no existían presiones profundas y sistemáticas para ello, podía resultar contraproducente e incluso riesgoso.

Hacia 1940, aún primaba la idea de que el sector agroexportador constituía el verdadero motor productivo de un país en transformación que, en parte gracias a la gradual recuperación de las ventas externas desde 1934, había logrado recobrar su impulso expansivo. Gracias a voces como la de Alejandro Bunge, para entonces se había abierto camino la convicción de que las agroindustrias y el sector manufacturero -cuya visibilidad había crecido en esos años- volcados sobre el mercado interno estaban en condiciones de expandir las fuentes de crecimiento y generar más empleos, y también que el Estado debía contribuir a empujar el proceso de diversificación productiva. Pero también existía un amplio acuerdo en torno a la noción de que estos sectores todavía dependían de la tracción proveniente del campo para continuar su carrera ascendente. Incluso voces crí- 
ticas de la orientación que el gobierno de la Concordancia le había impuesto al país solían enfatizar que el sector agroexportador seguía conformando el pilar central de su economía.

Algunos ejemplos ilustran este argumento. Un artículo aparecido en la revista radical Hechos e Ideas a propósito de la creación del CAN refrendaba todos los lugares comunes de la crítica social a la gran propiedad (los grandes latifundios constituyen una rémora atentatoria al interés colectivo y al progreso general y sostener una tesis contraria importaría divorciarse de la realidad) pero advertía de que somos y seremos por muchas generaciones un país esencialmente ganadero (Descalzo, 1939: 35).Y esa nación que sentía orgullo por su ganadería era un país con grandes estancias, que eran el núcleo de ese sector exportador concebido como el engranaje fundamental de la economía nacional. Tanto es así que, en la discusión parlamentaria del Programa de Reactivación de la Economía Nacional de 1940, conocido como Plan Pinedo, esos razonamientos volvieron a escucharse. En esa ocasión, el vocero del radicalismo afirmó que podrán caerse todas las chimeneas, pero mientras el campo produzca y exporte, el país seguirá comprando lo que necesite (citado en Llach, 1984: 530). El socialismo adoptó una posición similar (Nállim, 2008: 156).

Es importante tener presente que estos argumentos no iban dirigidos a seducir a la patronal agraria. También interpelaban a vastos segmentos de las clases medias y populares, urbanas y rurales. Si desde muy temprano el patrón de crecimiento exportador había dado forma a una sociedad compleja y diversificada, tanto en el campo como en la ciudad, este fenómeno se acentuó tras la Gran Guerra. A fines de los años treinta, no había duda alguna de que la sociedad urbana constituía el núcleo social y político del país, donde para entonces ya residían y trabajaban cerca de dos de cada tres habitantes. Los contemporáneos no ignoraban el punto. La Argentina, recordaba Alfredo Palacios en 1940, era un país agropecuario peculiar, toda vez que había superado en la proporción de vida urbana a los países industriales, excepto Inglaterra y Holanda ${ }^{21}$. La elevada productividad del sector rural era el factor determinante de una tasa de urbanización más elevada que la de las naciones de América del Norte y la de casi todos los países del Viejo Continente (en la enumeración de Palacios sólo falta Bélgica), y se encontraba entre las más elevadas del mundo. Sin duda, el derrumbe que acompañó a la Gran Depresión, con su secuela de desempleo y pobreza, le agregó tonalidades sombrías a este proceso de urbanización (Caimari, 2012). Aun así, ese país era consciente de que, si la modernidad y el progreso estaban cada vez más asociados a lo que sucedía en sus pujantes ciudades, todo ello era posible gracias a lo que exportaba el campo.

21. Congreso Nacional, Diario de Sesiones de la Cámara de Senadores, 1940, I, p. 579. 
Es cierto que en esos años se escucharon lamentos contra el despoblamiento de la campaña pampeana y de las provincias del interior, y que en ocasiones este tópico se articuló con una impugnación más general de la urbanización artificial y las flaquezas morales de la vida citadina ${ }^{22}$.Y en la huella abierta por estas denuncias surgió una literatura de entretenimiento dirigida a los consumidores urbanos que, de Don Segundo Sombra a Patoruzú, romantizaba la experiencia de la campaña, sin mayor referencia a sus problemas y conflictos. El éxito de público de estos productos culturales no es sorprendente, pues cierta sensibilidad nostálgica por la vida rural constituye un fenómeno habitual en sociedades muy urbanizadas (Mandler, 1997). En rigor, las visiones cerradamente negativas sobre la ciudad fueron ante todo discursos circunscriptos a pequeños círculos intelectuales que se arrogaban el derecho de opinar sobre lo que les convenía a los demás, pero que carecían de incidencia sobre las orientaciones políticas de las mayorías o sobre los núcleos donde se concentraba el poder.

Un trabajo de Emilio Coni publicado en 1942 nos ayuda a poner las cosas en su lugar. Campo y ciudad: Causas de la concentración urbana argentina partía de la premisa de que el crecimiento urbano, lejos de perjudicar al campo, más bien lo favorecía. Al compás de la urbanización, razonaba este profesor iconoclasta, también crecía la demanda de bienes rurales. Este proceso tan recelado por Alejandro Bunge y otros pensadores de inclinaciones conservadoras o nostálgicas era, en rigor, el resultado directo del éxito del campo, y la mejor prueba del secular proceso de incremento de la productividad agraria. La concentración urbana, afirmaba Coni, no constituye algo artificial como lo cree la mayoría de las gentes. En el horizonte de Coni el ascenso urbano era parte de un proceso de cambio sociocultural que no era necesario ni conveniente obstaculizar. Era, ante todo, la exteriorización de la pujanza de una sociedad en evolución hacia el progreso, y reflejaba la aspiración del hombre a una vida material mejor (Coni, 1942: 3, 5, 12). El progreso sociocultural estaba asociado a la urbanización, cuya condición de posibilidad y contracara era un campo productivo y especializado.

No hay duda de que, cuando Coni presentaba estos argumentos, el anhelo de una vida más plena había ganado el corazón de muchos habitantes de la campaña, que eran bien conscientes de que el mundo urbano poseía una oferta educativa y laboral más diversificada y de superior calidad, así como más y mejores opciones para el pleno disfrute de la vida. Los jóvenes, en particular, sentían con especial fuerza el hechizo de sus expansivas industrias culturales y sus vastos y diversos espacios de sociabilidad (Coni, 1942: 12). Es en este marco que debemos colocar la historia de Eva Duarte, esa joven de Los Toldos cautivada por las luces de la ciudad, a la que llegó en 1935, y, una década más

22. Ejemplos en BALSA (2012). 
tarde, ya convertida en actriz, sedujo al coronel Perón. Eva fue una entre muchas. De hecho, no fue sólo la crisis agraria, sino esa aspiración a una vida mejor, material, pero también en lo referido a relaciones y experiencias, lo que estimuló la migración desde las campañas pampeanas hacia las urbes litorales. Esta migración comenzó antes de la Depresión -ya en 1929 Campolieti se lamentaba de que los hijos de colonos poca tendencia tienen a dedicarse al arte paterno [...] estamos en uno de los tantos ejemplos de una gran ciudad que ejerce su influencia sobre el campo (Campolieti, 1929: 259)- y continuó luego de 1935, cuando lo peor de la crisis agrícola había pasado. Este movimiento humano no sólo continuó reforzando la incidencia de la ciudad en la vida social y política del país, sino que, en la medida en que sirvió para trasportar los sueños y esperanzas de muchos hombres y mujeres del campo hacia un nuevo horizonte, objetivamente contribuyó a marginar de la agenda política a las demandas de los productores agrícolas y la población rural. Ante el empuje de la ciudad, los voceros del sueño farmer se estaban quedando solos.

Este sentimiento de orfandad fue percibido por varios expertos agrícolas que alzaron la voz en nombre de los que permanecían en las chacras. Entre ellos estaba Lázaro Nemirovsky. Los partidos actuales forman una amalgama latifundista-ganadera-industrial que defienden los intereses de la ciudad, descuidando deliberadamente los problemas del campo, se quejaba este militante agrario en un estudio en el que terminaba instando a los hombres de la FAA a organizarse como una fuerza política (Nemirovsky, 1933: 202).

Como era previsible, esta invitación fue rechazada, entre otras cosas porque esos agricultores a los que, con visión sesgada y anacrónica, hombres como Nemirovsky juzgaban como los únicos grupos auténticamente valiosos del tejido productivo, conformaban un sector cada vez más minoritario de la población y del electorado (según el censo agropecuario de 1937, Buenos Aires, Córdoba y Santa Fe tenían unos ochenta mil arrendatarios agrícolas sobre una población total que se acercaba a los 5,5 millones, de los cuales poco más de un cuarto eran varones adultos), además de difícil de organizar. En estas circunstancias, el partido agrario capaz de liderar la lucha contra el latifundio y la explotación de los intereses urbanos era una quimera que, al igual que el programa de socialización de la tierra propuesto por el comunista Boglich, ni siquiera los chacareros más osados políticamente creyeron posible perseguir.

Visto en perspectiva, este desamparo ayuda a explicar la reiterada y casi siempre ingrata búsqueda de aliados entre las fuerzas políticas que signó a la historia de la FAA que, tras algunos tanteos con el socialismo, pasó a cortejar al radicalismo y al conservadurismo, para terminar tendiéndole la mano a los militares de la Revolución de Junio de 1943. Si a lo largo de las décadas de entreguerra sus esfuerzos no rindieron muchos frutos fue por- 
que, al margen de lo que estaban dispuestos a ofrecerles los distintos interlocutores que eligieron para hacer avanzar su causa, la peculiar combinación de enorme gravitación económica de la economía exportadora y creciente marginalidad social y política de la comunidad de agricultores restó atractivo y viabilidad a las propuestas de aquellos que querían ver realizado el sueño de un campo dominado por empresas familiares en tierra propia.

Pero si ese llamado cayó en el vacío fue también porque, poco a poco y de manera silenciosa, muchos de los habitantes de los pueblos rurales y de las chacras le fueron dando la espalda a la causa de la agricultura propietaria. Conforme avanzaba el período de entreguerras, la respuesta para sus dificultades, pero también para sus ambiciones y esperanzas, fue girar la vista hacia la gran ciudad. De allí que, incluso antes de que Perón ofreciese un nuevo horizonte para desplegar la imaginación política de los argentinos -el de un país animado por el sueño industrial y el ideal de la justicia social-, el programa de la agricultura en tierra propia, que desde Sarmiento a Juan B. Justo constituyó la base sobre la que debía erigirse una nueva sociedad, terminó convertido en el reclamo de un grupo de interés específico que, además de un peso decreciente en la vida colectiva, estaba identificado con un proyecto de sociedad que tenía más pasado que futuro.

\section{AGRADECIMIENTOS}

Una versión previa de este trabajo fue presentada en el congreso «Transiciones en la agricultura y la sociedad rural: Los desafíos globales de la historia rural", Santiago de Compostela, 20-23 de junio de 2018. Agradezco los comentarios allí recibidos, así como las sugerencias de los editores y los evaluadores de la revista Historia Agraria.

\section{REFERENCIAS}

Adelman, J. (1989). Una cosecha esquiva: Los socialistas y el campo antes de la Primera Guerra Mundial. Anuario del IEHS, (4), 293-333.

AdELMAN, J. (1994). Frontier Development: Land, Labour, and Capital on the Wheatlands of Argentina and Canada, 1890-1914. Oxford: Oxford University Press.

AMARAL, S. (2004). Advertencia preliminar. En K. KAERGER, La agricultura y la colonización en Hispanoamérica: Los estados del Plata. Buenos Aires: Academia Nacional de la Historia.

ARCONDO, A. (1980). El conflicto agrario argentino de 1912: Ensayo de interpretación. Desarrollo Económico, 20 (79), 351-381. 
BALsA, J. (2011). Chacareros en la gran ciudad. En M. Z. Lobato (Comp.), Buenos Aires: Manifestaciones, fiestas y rituales en el siglo XX (pp. 177-202). Buenos Aires: Biblos.

BALSA, J. (2012). Formaciones discursivas y disputas por la hegemonía en torno a los modelos de desarrollo agrario. En J. BALSA \& S. LÁzZARo, Agro y política en Argentina. I: El modelo agrario en cuestión, 1930-1943 (pp. 35-117). Buenos Aires: Ciccus.

Barsky, O. \& Gelman, J. (2001). Historia del Agro Argentino: Desde la Conquista hasta fines del siglo XX. Buenos Aires: Mondadori.

Blanco, M. (2007). Reforma en el agro pampeano: Arrendamiento, propiedad y legislación agraria en la provincia de Buenos Aires. Bernal: Universidad Nacional de Quilmes.

BonAUd, M. \& Godoy, C. (1985). Una corporación y su inserción en el proyecto agroexportador: la Federación Agraria Argentina (1912-1933). Anuario, (11), 151-216.

BogLICH, J. (1933). El problema agrario y la crisis actual. Buenos Aires: Aras.

Boglich, J. (1937). La cuestión agraria. Buenos Aires: Claridad.

Caimari, L. M. (2012). Mientras la ciudad duerme: Pistoleros, policías y periodistas en Buenos Aires, 1920-1945. Buenos Aires: Siglo XXI Editores.

Campolieti, R. (1929). La organización de la agricultura argentina. Buenos Aires: Aquino \& cía.

Coni, E. A. (1942). Campo y ciudad: Causas de la concentración urbana argentina. Buenos Aires: Facultad de Agronomía y Veterinaria, Imprenta de la Universidad.

Descalzo, E. (1939). La realidad agropecuaria argentina. Hechos e Ideas, (34).

Di NúBILA, D. (1998). La época de oro: Historia del cine argentino. Buenos Aires: Ediciones del Jilguero.

DJENDEREDJAN, J., BEARZotTi, S. \& MARTIRÉN, J. L. (2010). Expansión agrícola y colonización en la segunda mitad del siglo XIX. 2 vols. Buenos Aires: Teseo.

Dyson, L. K. (1982). Red Harvest: The Communist Party and American Farmers. Lincoln: University of Nebraska Press.

Federación Agraria Argentina (1939). Federación Agraria Argentina: Apuntes para su historia, 1912-1928. Rosario: Talleres gráficos Emilio Fenner.

FresCo, M. A. (1941). Acción agraria y colonizadora de mi gobierno: Promesas y realidades. Buenos Aires: [s. n.].

GarCía, J. M. (1972). El campo argentino a 60 años del Grito de Alcorta. Buenos Aires: Ediciones Centro de Estudios.

GERCHUNOFF, P. (2016). El eslabón perdido: La economía política de los gobiernos radicales (1916-1930). Buenos Aires: Edhasa.

GiRBAL DE BLACHA, N. (1989). La granja, una propuesta alternativa de coyuntura para el agro pampeano, 1910-1930. Canadian fournal of Latin American and Caribbean Studies-Revue canadienne des études latino-américaines et carä̈bes, 14 (28), 71-115. 
Girola, C. D. (1904). Investigación agrícola en la República Argentina: Preliminares, notas y observaciones sobre los trabajos efectuados hasta febrero de 1904. Buenos Aires: Compañía Sud-Americana de Billetes de Banco. (Anales del Ministerio de Agricultura, t. 1).

GiUsti, R. (1937). El drama rural argentino. Nosotros, 2 (20), 241-264.

Grela, P. (1985). El Grito de Alcorta. Buenos Aires: Centro Editor de América Latina. HALPERIN Donghi, T. (1987). Canción de otoño en primavera: Previsiones sobre la crisis de la agricultura cerealera argentina (1894-1930). En T. HALPERIN DONGHI, El espejo de la historia: Problemas argentinos y perspectivas latinoamericanas (pp. 253-277). Buenos Aires: Sudamericana.

HoRA, R. (2002). Los terratenientes de la pampa argentina: Una historia social y política, 1860-1945. Buenos Aires: Siglo XXI Editores.

HorA, R. (2010). Historia económica de la Argentina en el siglo XIX. Buenos Aires: Siglo XXI Editores.

HorA, R. (2012). La evolución del sector agroexportador argentino en el largo plazo, 1880-2010. Historia Agraria, (58), 175-211.

HoRA, R. (2018). ¿Cómo pensaron el campo los argentinos? Y cómo deberían pensarlo hoy, cuando ese campo ya no existe. Buenos Aires: Siglo XXI Editores.

Horowitz, J. (2001). Cuando las élites y los trabajadores coincidieron: La resistencia al programa de bienestar patrocinado por el gobierno argentino, 1923-24. Anuario IEHS, (16), 109-128.

KAERGER, K. (2004). La agricultura y la colonización en Hispanoamérica: Los estados del Plata. Buenos Aires: Academia Nacional de la Historia.

LahitTe, E. (1905). La propiedad rural. Boletín del Ministerio de Agricultura, (III), 72104.

Llach, J. J. (1984). El Plan Pinedo de 1940, su significado histórico y los orígenes de la economía política del peronismo. Desarrollo Económico, 23 (92), 515-556.

Lobos, E. (1925 [1917]). Introducción. En M. A. CÁRCANO, Evolución histórica del régimen de la tierra pública, 1810-1916. Buenos Aires: La Facultad.

MANDLER, P. (1997). Against "Englishness": English Culture and the Limits to Rural Nostalgia, 1850-1940. Transactions of the Royal Historical Society, (7), 155-175.

MArotTA, F. P. (1932). El verdadero nacionalismo económico argentino. En F. P. MAROTTA, Tierra y patria: Los argentinos debemos realizar la segunda expedición al desierto. Buenos Aires: Mercatali.

MíGueZ, E. J. (2006). ¿Veinte años no es nada?: Balance y perspectivas de la producción reciente sobre la gran expansión agraria. En J. GeLMAN (Comp.), La historia económica argentina en la encrucijada: Balances y perspectivas (pp. 309-229). Buenos Aires: Prometeo.

Míguez, E. J. (2008). Historia económica de la Argentina: De la conquista a la crisis de 1930. Buenos Aires: Sudamericana. 
Míguez, E. J. (2017). Del feudalismo al capitalismo tardío: ¿El fin de la historia... agraria? Boletín del Instituto de Historia Argentina y Americana "Dr. Emilio Ravignani», (46), 180-204.

NÁllim, J. (2008). Between Free Trade and Economic Dictatorship: Socialists, Radicals, and the Politics of Economic Liberalism in Argentina, 1930-1943. Canadian fournal of Latin American and Caribbean Studies/Revue canadienne des études latino-américaines et caraïbes, 33 (65), 139-174.

Nemirovsky, L. (1933). Estructura económica y orientación política de la agricultura en la Argentina. Buenos Aires: Menéndez.

Newton, R. C. (1997). El fascismo y la colectividad ítalo-argentina, 1922-1945. En I. KLICH \& M. RAPOPORT (Comps.), Discriminación y racismo en América Latina (pp. 367-392). Buenos Aires: Grupo Editor Latinoamericano.

OdDone, J. (1930). La burguesía terrateniente argentina: Capital federal, Buenos Aires, territorios nacionales. Buenos Aires: Talleres gráficos La Vanguardia.

PUIGgrós, R. (1956). Historia critica de los partidos políticos argentinos. Buenos Aires: Argumentos.

Ramírez, D. (2011). Horacio Giberti: Memorias de un imprescindible. Buenos Aires: Centro Cultural de la Cooperación Floreal Gorini/Universidad Nacional de Quilmes.

RAÑÁ, E. S. (1904). Investigación agrícola en la República Argentina, provincia de Entre Ríos. Buenos Aires: Biedma.

SMITH, P. H. (1967). Los radicales argentinos y la defensa de los intereses ganaderos. Desarrollo Económico, 7 (25), 795-829. 